\title{
Bentuk Pertunjukan Wayang Kulit Bali Lakon Bhima Swarga dalam Upacara Pitra Yadnya
}

\author{
I Wayan Sugita ${ }^{1}$ I Gede Tilem Pastika ${ }^{2}$ \\ ${ }^{12}$ Universitas Hindu Negeri I Gusti Bagus Sugriwa Denpasar \\ ${ }^{1}$ wayansugita2@gmail.com, ${ }^{2}$ tilempastikaigede@gmail.com
}

\begin{abstract}
The Balinese shadow puppet show has a connection between the story that is told and the context of the yadnya ceremony. Mahabharata is an epic that is always the source of stories in Balinese shadow puppet shows, the storylines are often improvised by the puppeteers in the performances. Kawi dalang makes the story used more connected to the context of the implementation of the yadny ceremony. One of the carangan stories that are often performed is the story of Bhima Swarga at the Pitra Yadnya ceremony. However, in the performance, the audience did not see this meaningful and unique performance. Therefore, it is necessary to conduct a study to find out the form of the performance, so that the reader knows the aspects of the form in the Balinese shadow puppet show Bhima Swarga story. The method used in this research is descriptive qualitative. The results of this study are in the form of a description and analysis of the synopsis, the structure of the performance, the form of the puppet characterizations, the language and vocals used, the musical accompaniment, the offerings used, and the stage set in the Balinese shadow puppet show Bhima Swarga story. all aspects of the form are integrated into a show that elevates Bhima as the central character and the story that is told can be used as an example in life to serve the ancestors.
\end{abstract}

Keywords: Form Of Shadow Puppet Performances; Balinese Shadow Puppet In Pitra Yadnya; Bhima Swarga Stories

\begin{abstract}
Abstrak
Pertunjukan wayang kulit Bali memiliki keterkaitan antara cerita yang dibawakan dengan konteks kegiatan upacara yadnya. Mahabharata sebagai sebuah epos yang senantiasa menjadi sumber cerita dalam pertunjukan wayang kulit Bali kerap kali diimprovisasikan aspek alur ceritanya oleh para dalang dalam pertunjukan. Kawi dalang menjadikan lakon yang digunakan lebih terhubung dengan konteks pelaksanaan upacara yadnya. Salah satu lakon carangan yang sering kali dipentaskan adalah Lakon Bhima Swarga (LBS) pada upacara Pitra Yadnya. Namun dalam pementasanya penonton tidak menyaksikan pertunjukan yang penuh makna dan unik ini. Maka dari itu perlu dilakukan sebuah kajian untuk mengetahui bentuk pertunjukanya, agar pembaca mengetahui aspek bentuk dalam pertunjukan wayang kulit Bali LBS. Metode yang digunakan dalam penelitian ini adalah kualitatif deskriptif. Hasil dari penelitian ini adalah berupa deskripsi dan analisis tentang sinopsis, struktur pertunjukan, bentuk penokohan wayang, Bahasa dan vokal yang digunakan, musik iringan, sesajen yang digunakan, dan bentuk panggung dalam pertunjukan wayang kulit Bali LBS. keseluruhan aspek bentuk tersebut terintegrasi dalam sebuah pertunjukan yang mengangkat Bhima sebagai tokoh sentral dan cerita yang dibawakan dapat dijadikan contoh pada kehidupan untuk berbakti kepada para leluhur.
\end{abstract}

Kata Kunci: Bentuk Pertunjukan Wayang; Wayang Kulit Bali Dalam Pitra Yadnya; Lakon Bhima Swarga 


\section{Pendahuluan}

Pertunjukan wayang merupakan satu dari beberapa jenis seni pertunjukan lain seperti tari, musik, teater dan lain sebagainya. Kesenian wayang ditenggarai sebagai salah satu kesenian yang sudah ada dari zaman prasejarah. Secara historis beberapa peneliti mengungkapkan bahwa sejarah wayang ditemukan indikasi bahwa wayang sudah ada sejak 1500 SM (Awalin, 2018: 78). Keberadaan wayang yang sudah sejak lama terhubung dengan aspek kepercayaan manusia pada zaman prasejarah terhadap kekuatan di luar kekuatan manusia, yang mencakup paham animisme, dinamisme, dan totemisme. Poespaningrat (2005: 5) menyatakan bahwa, masyarakat jaman prasejarah mempercayai adanya roh khususnya roh leluhur atau Hyang, masyarakat melakukan ritual penyembahan dengan tujuan memohon perlindungan dari gangguan gaib, maupun memohon berkah untuk kehidupanya.

Berbicara tentang sejarah seni pertunjukan wayang kulit Bali, belum ditemukan sumber yang pasti sejak kapan kemunculannya pertama kali. Akan tetapi ada dugaan, sejarah wayang kulit Bali, tidak bisa dilepaskan dari sejarah wayang kulit pada umumnya, terutama wayang kulit Jawa. Dari segi bentuknya, seni wayang dapat dibagi lagi yakni ada wayang kulit, wayang golek dan wayang wong. Wayang kulit terbuat dari kulit sapi, kerbau atau kulit binatang lainnya seperti kulit rusa ataupun kulit sapi. Wayang golek terbuat dari kayu dan kain, serta pernikpernik lainnya. Sedangkan wayang wong dimainkan oleh manusia. Di Indonesia, dua daerah pendukung besar tradisi wayang kulit adalah Jawa dan Bali. Jika dilihat secara konsepsi, wayang kulit Bali dan wayang kulit Jawa (juga disebut Wayang Purwa) adalah sama. Namun jika dilihat dari bentuk dan penyajiannya, masing-masing mempunyai pola tersendiri. Dua epos besar tersohor yaitu Ramayana dan Mahabharata menjadi cerita pokok pada Wayang Purwa Jawa dan Wayang Ramayana serta Wayang Parwa Bali (wayang yang menggunakan epos Mahabharata).

Epos Mahabharata terus berkembang dan diadopsi oleh budaya lokal. Di Indonesia, beberapa bagian cerita disalin ke berbagai bahasa daerah. Dalam perkembangan kemudian, cerita Mahabharata digubah dalam bentuk kakawin, yakni puisi lawas dengan metrum India berbahasa Jawa Kuno. Karya sastra kakawin tersebut antara lain: Kakawin Arjunawiwaha, gubahan Mpu Kanwa. Kakawin Bharatayuddha, yang digubah oleh Mpu Sedah dan belakangan diselesaikan oleh Mpu Panuluh. Kakawin Hariwangæa pada masa pemerintahan Jayabaya. Mpu Panuluh juga diperkirakan pula menggubah Kakawin Gatotkacâsraya pada masa raja Kertajaya (1194-1222 M) dari Kediri. Beberapa kakawin lain yang mengisahkan penggalan Mahabharata yakni Krishnayana (karya Mpu Triguna) dan Bhomântaka (pengarang tidak dikenal). Kedua kakawin itu, diperkirakan ditulis pada Zaman Kerajaan Kediri. Kemudian Kakawin Pârthayajña ditulis oleh Mpu Tanakung di akhir zaman Majapahit. Salinan naskah-naskah kuno yang tertulis dalam lembar-lembar daun lontar tersebut tersimpan di Bali (Zoetmulder, 1984). Dalam Pertunjukan wayang kulit Bali, Mahabharata juga disebut Sanghyang Astadasaparwa, yang tidak pernah disinggung dalam versi India. Hal itu bisa dilihat dalam penggalan prolog pertunjukan wayang kulit Bali sebagai berikut.

Mijil....Sanghyang ringgit amulahcara wetinuduh denira Sanghyang Pramakawi, ri....pangekan ira Sang Guru Reka, Paran risparatingkahira, Sawetning sampun wus puput jangkep ingetang denira Sanghyang Asta Dasa Parwa Carita, Ripangiket ira Bhagawan Kresna Dwipayana Wyasa.

Hal unik lainya yang terjadi adalah proses improvisasi alur cerita Mahabharata yang dilakukan oleh seniman dalang dalam pertunjukan wayang kulit Bali uyang biasa disebut sebagai kawi dalang. Cerita kawi dalang, menurut Wicaksana (wawancara 22 Maret 2021), artinya cerita yang dikarang oleh seorang dalang untuk pertunjukannya. Akan tetapi, cerita yang dikarangnya itu, tidak boleh bertentangan dengan babon atau cerita induknya. Misalnya, tokoh Bhima dan Arjuna tetap disebut putra Kunti, bukan putra seorang raksasi. Kecuali bermaksud menyebut Bhima dan Arjuna palsu. 
Seorang dalang punya hak mengarang cerita selain untuk menunjukkan kreativitas, juga memiliki seorang dalang dituntut untuk mampu menyelaraskan lakon yang dibawakan dengan konteks pertunjukanya, terlebih lagi pertunjukan wayang kulit Bali dalam sebuah upacara Yadnya. Hal itu mungkin dilakukan, agar seorang dalang tidak dituduh sebagai plagiator. Hal itu bisa disimak dalam penggalan Penyacah Parwa sebagai prolog dalam pertunjukan wayang kulit Parwa sebagai berikut:

....sawetning sampun wus puput jangkep engitang denira Sanghyang Astadasa Parwa Carita, ripangiket denira Bhagawan Krishna Dwipayana Wyasa....

Ucapan prolog itu pada intinya menyatakan, bahwa Astadasa Parwa atau Mahabharata dikarang oleh Bhagawan Wyasa. Kemudian dalang memenggal cerita epos Mahabharata sesuai dengan keinginan dalang. Hal itu bisa disimak dalam pertunjukan wayang kulit Parwa dengan dalang Ida Bagus Ngurah dari Buduk, Badung sebagai berikut:

Saksana mijil.....Sanghhyang Kawiswaramurti tan sah anugel ripunang tattwa carita.

Caritanan.....(menyebutkan lakon carita)...

Dalam kesenian wayang kulit Bali, tidak terhitung cerita carangan yang dikarang seorang dalang. Cerita carangan itu antara lain Bhima Swarga. Lakon Bhima Swarga (LBS) menceritakan tentang perjalanan dan sikap heroik Bhima yang menyanggupi permintaan ibunya agar dapat membebaskan arwah leluhurnya dari dasar kawah neraka sebelum Puri Indraprasta melaksanakan upacara Yadnya besar. LBS sangat terkait dengan konteks munggahang pitara atau mengangkat derajat leluhur sehinga menjadi Bhatara Hyang Guru dalam kepercayaan masyarakat Bali. Maka dari itu pertunjukan wayang kulit Bali dengan LBS selalu ditampilkan pada upacara Pitra Yadnya.

Selain berfungsi sebagai pelengkap sarana ritual, pertunjukan wayang kulit Bali LBS berfungsi sebagai sarana pendidikan agama dengan antawacana dalang dalam pertunjukanya, serta mengandung fungsi hiburan untuk para penontonya. Meskipun demikian, pada pertunjukanya sangat jarang disimak dan disaksikan dengan baik oleh penonton karena kondisi dan situasi pada pelaksanaan upasara pitra yadnya. Pertunjukan wayang yang kerap kali mendapatkan perhatian dan mengundang antusisas penonton adalah pertunjukan wayang yang didominasi oleh berbagai macam lelucon, atau sebatas hiburan. Dibia (1995: 51-68) menyebutkan pergeseran yang terjadi dalam pertunjukan wayang adalah dari wacak ke kocak, dari tontonan yang didominasi oleh pesan-pesan moral, pendidikan dan lainya berubah menjadi tontonan yang hanya bertujuan membuat penonton tertawa. Senada dengan yang diungkapkan Masroer (2015: 45-46) Ia menyatakan bahwa, terdapat pergeseran peran dari pertunjukan wayang yang sebelumnya penuh dengan makna dan aspek pendidikan yang dibawakan dengan berbagai macam simbol serta aspek religius-magis pada pertunjukanya, sekarang hanya menjadi sebuah hiburan belaka dan hanya itu yang dinanti-nanti oleh penontonya. Maka dari itu pertunjukan wayang kulit Bali LBS yang sarat akan makna religius-magis serta pendidikan menarik untuk dikaji lebih dalam, untuk mengetahui bentuk pertunjukan yang meliputi jenis wayang yang digunakan, cerita, penggunaan bahasa, upakara, dan bentuk penataan panggung pertunjukan yang digunakan dalam pertunjukanya pada upacara Pitra Yadnya.

\section{Metode}

Penelitian ini menggunakan metode deskriptif kualitatif. Tulisan ini merupakan bagian dari penelitian kompleks terhadap keberadaan Lakon Bhima Swarga dalam Seni Pertunjukan Wayang Kulit Bali, dimana secara keseluruhan kajian dilakukan dengan berfokus pada aspek bentuk, fungsi dan makna. Hasil penelitian ini dijadikan beberapa artikel ilmiah karena dirasakan perlu pembahasan dan pengamatan secara mengkhusus pada sebuah topik yang digunakan. Dalam tulisan ini secara mengkhusus membahas tentang bentuk pertunjukan wayang kulit Bali Lakon Bhima Swarga dalam upacara Pitra Yadnya. Penelitian ini dilakukan di Desa Sukawati, Kecamatan Sukawati, Kabupaten Gianyar, Provinsi Bali. Pemilihan lokasi 
dikarenakan ketersediaan data, dan keberadaan Dalang yang mudah ditemukan serta Sukawati memiliki gaya pertunjukan Wayang Kulit Bali yang dijadikan pakem dalam seni pertunjukan Wayang Kulit Bali secara umum. Teknik pengumpulan data yang digunakan adalah observasi, wawancara, studi kepustakaan dan studi dokumen. Penentuan informan dilakukan dengan menggunakan teknik purposive sampling.

\section{Hasil dan Pembahasan}

Semua kesenian pertunjukan, termasuk pertunjukan seni wayang kulit memiliki bentuk. Menurut Djelantik dalam Arnailis (2007:87), bentuk atau apapun wujudnya adalah sebuah kenyataan yang tampak secara nyata, baik yang dapat dilihat langsung dengan kasat mata, maupun dapat didengar dengan alat pendengar. Bentuk juga merupakan wujud yang abstrak namun dapat dibayangkan dan berada dalam wilayah imajinasi manusia. Sugiartha (2015) menyatakan bahwa jika ditinjau secara konseptual bentuk merupakan apa yang napak dan hal tersebut memberikan sentuhan perbedaan jika dipersepsi dan diidentifikasi. Bentuk LBS dalam seni pertunjukan wayang, dapat dibagi dalam beberapa bentuk yaitu: (1) Sinopsis LBS; (2) Struktur pertunjukan LBS; (3) bentuk penokohan; (4) pengiring seni pertunjukan LBS; (5) sesajen yang digunakan dan (6) bentuk panggung pertunjukan.

\section{Sinopsis Pertunjukan Wayang Kulit Bali LBS}

Sinopsis adalah ringkasan karangan yang biasanya diterbitkan bersama dengan karangan asli yang menjadi dasar sinopsis (KBBI). Defisini tersebut juga sesuai dengan pengertian yang diberikan Pamusuk Eneste dalam buku Penyuntingan Naskah karya, bahwa sinopsis adalah ringkasan pendek dari bentuk karangan asli yang panjang. Bentuk sinopsis biasanya singkat, padat, dan jelas. Isi ringkasan bersifat persuasif dengan tujuan pembaca tertarik untuk membaca atau melihat karya aslinya. Mengacu pada definisi tersebut, dan LBS yang sering dipentaskan oleh Dalang Wayan Narta seorang dalang senior dari Desa Sukawati, Gianyar, yakni sebagai berikut.

Pada suatu hari, Dewi Kunti memanggil putranya Bhima. Dalam pertemuan itu, Dewi Kunti mengutarakan tentang persiapan upacara yadnya yang akan dilangsungkan di Merajan Agung istana. Dewi Kunti menuturkan, bahwa dirinya telah menerima sabda dari Dewata, bahwa upacara tidak bisa dilaksanakan, jika masih ada dalam keadaan leteh, yaitu roh Pandu dan Dewui Madri masih ada dalam kawah neraka. Oleh karena itulah, Dewi Kunti meminta kepada semua anaknya untuk membebaskan roh Pandu dan Dewi Madri, dari kawah neraka. Namun Yudhisthira, Arjuna, Nakula dan Sahadewa menyatakan tidak dapat melaksanakan perintah ibunya, karena mengaku tidak mampu.

Oleh karena itulah Dewi Kunti meminta kepada Bhima agar segera berangkat ke sorga untuk membebaskan roh leluhurnya itu. Bhima menyatakan bersedia dan senang hati serta penuh semangat melaksanakan perintah ibunya itu. Bhima lalu berangkat ke sorga bersama Dewi Kunti dan semua saudara-saudaranya. Berkat ajian angkus prana, Bhima mempersilahkan ibu dan semua saudaraya masuk ke dalam tubuhnya. Beberapa lama kemudian, Bhima tiba di Tegal Penangsaran. Dalam perjalanannya, mereka menemui berbagai rintangan yang disebut pengadang-ngadang, seperti rumput berdaun senjata taji, tumbak, ikan julit berkepala raksasa, buaya, catur sanak. Bhima kemudian berperang dengan penghuni sorga, seperti binatang dan sebagainya.

Oleh karena keadaan sorga menjadi kacau, Sang Suratma mengetahui kejadian tersebut. Atas laporan Sang Suratma, Jogor Manik sebagai penjaga pintu kawah Candragomuka Sanghyang Yama sebagai Hakim sorga menjadi murka. Sanghyang Yama segera menemui Bhima, apa tujuannya ke sorga. Bhima menjelaskan bahwa ia memohon agar roh Pandu dan Dewi Madri dibebaskan. Bhima hanya memohon dua atma, yakni hanya berjenis lakiperempuan. Sanghyang Yama mememenuhi permintaan Bhima. Bhima segera terjun ke kawah, 
untuk mencari atma Pandu dan Dewi Madri yang menjadi intip (kerak) kawah yang panas itu. Oleh karena berada di dasar kawah, Bhima mengangkat banyak atma. Ketika diprotes oleh Sanghyang Atma, Bhima mengatakan, bahwa ia hanya mengangkat atma laki dan perempuan, dan tidak ada mengambil atma yang banci. Sanghyang Yama marah dan menantang Bhima untuk berkelahi. Bhima meladeni dan mencekik Sanghyang Yama. Sanghyang Yama pun menyerah dan menyatakan bersedia mengambil atma Pandu dan Madri di dasar kawah. Namun janji itu tidak dilaksanakan oleh Sanghyang Yama. Kawah itu kemudian dibalik oleh Bhima. Ia hanya mendapatkan kotoron besi sebagai kerak kawah. Bhima kemudian memanggil ibunya Dewi Kunti, untuk memastikan apakah atma Pandu dan Dewi Madri itu berupa kerak kawah. Setelah yakin itu benar atma Pandu dan Madri, Bhima memanggil kakaknya, Yudhisthira, dan adik-adiknya Arjuna, Nakula dan Sahadewa.

Dewi Kunti memerintahkan agar Nakula dan Sahadewa menyembah dua atma itu supaya wujudnya lebih sempurna. Setelah itu, kotoran besi itu menjadi tulang belulang Pandu dan Dewi Madri. Kemudian Arjuna menghaturkan sembah, lalu dilanjutkan oleh Yudhisthira. Setelah itu, keduanya berubah menjadi sesosok manusia seperti patung. Kunti lalu memerintahkan Bhima untuk melakukan sembah agar wujud Pandu dan Madri lebih sempurnna. Bhima menolak perintah ibunya. Nakula dan Sahadewa lalu memiliki siasat. Ia mengatakan, bahwa jeriji Bhima kanan-kiri tidak sama. Setelah Bhima mencakupkan tangan untuk memastikan ukuran jeriji tangannya, di saat itu Bhima dipandang sudah menghaturkan sembah. Setelah sempat marah, karena merasa ditipu, Bhima mohon tirta pawitra Dewata Nawa Sanga. Setelah sempat bertarung dengan para dewata, Bhima sempat tewas oleh Dewa Bayu. Namun Bhima dihidupkan kembali oleh Sanghyang Tunggal. Sanghyang Tunggal lalu menganugerahi tirta pawitra. Dengan disucikannya roh Pandu dan Madri, maka upacara yang digelar di Merajan Agung Pandawa dapat dilangsungkan dengan lancar dan sukses.

\section{Struktur Pertunjukan Wayang Kulit Bali LBS}

Berdasarkan pengamatan dan informasi informan, pertunjukan wayang kulit LBS selalu dipergelarkan menurut tradisi yang turun temurun. Hal itu disebabkan, pertunjukan wayang dengan mengangkat LBS, lebih sering dipentaskan dalam upacara Pitra Yadnya. Hal itu diakui Jero Dalang Wayan Narta. Wayan Narta sering mementaskan LBS dalam upacara Pitra Yadnya. Menurut Narta (wawancara, 1 Agustus 2021) pertunjukan wayang kulit Bali LBS memang paling sering dipentaskan dalam upacara Pitra Yadnya, karena lakon ini memiliki hubungan yang erat dengan upacara penyucian roh leluhur atau roh seseorang yang sedang diupacarai dalam upacara tersebut. Narta mengakui, tiap-tiap dalang memiliki pakem tersendiri dalam mementaskan pertunjukan wayang kulit bali LBS tersebut, sesuai dengan selera seninya. Dalang dalam situasi ini menjadi seorang sutradara, penulis naskah, dan aktor secara bersamaan. Sebagai penulis naskah, dalang bisa saja menuliskan kembali cerita yang dibawakan dalam naskah yang baik atau naskah yang absurd sekalipun. Naskah yang baik adalah naskah yang alur ceritanya yang rapi, cerdas, dialog yang tertata, dan penokohan yang pasti. Sedangkan naskah absurd adalah naskah yang unik, ditulis dengan gaya tersendiri, alur cerita susah untuk ditebak (Esslin, 2008: 3).

Dalam setiap pertunjukan wayang, dalang memiliki tujuan yang bersifat commeratif yaitu mengingat, menggali dan merekonstrusksi pemaknaan dari cerita yang dibawakan menjadi sebuah dialog antara karakter wayang (Prayoga, 2018: 210). Hal tersebut membuat satu pertunjukan wayang dengan pertunjukan lainya dengan dalang yang berbeda, maka berbeda pula pola tafsir terhadap sebuah makna dalam cerita yang dibawakan. Akan tetapi, meskipun berbeda, namun fungsi dan maknanya secara umum tidak berbeda. Narta sendiri terkadang menampilkan pakem yang tidak persis sama dalam beberapa pementasan, karena tergantung pada situasi dan kondisi yang ada. Panjang pendeknya durasi seringkali 
mempengaruhi pakem pementasannya. Adapun salah satu pertunjukan wayang kulit bali LBS yang pernah dipentaskan Narta memiliki struktur sebagai berikut:

Pada babak I, pertunjukan diawali oleh tabuh pategak. Tabuh Pategak meruakan penampilan awal sebagai pembuka sebuah pertunjukan secara menyeluruh (Ardana, 2020: 22). Pada saat yang bersamaan, dalang mempersiapkan pertunjukan dengan mengucapkan doa-doa. Setelah melakukan persembahyangan dengan sarana sesajen itu, dalang membuka keropak atau gedog wayang. Dua wayang pemurtian yaitu Wisnumurti dan Ludramurti dikeluarkan. Setelah itu, dilanjutkan tari wayang Kayon yang dalam budaya Jawa disebut Gunungan. Kayonan dalam babak ini merupakan simbol alam semesta. Secara visual dapat dilihat berbagai macam ornamen seperti tumbuh-tumbuhan, kayu, gunung, binatang, dan isi alam semesta lainya dalam kayonan. Selain sebagai penggambaran alam secara fisik, kayonan juga penggambaran psikis yang abstrak dari alam ini. Jika ditinjau dari penamaan wayang kayonan, berasal dari bahasa Kawi yaitu kayun yang dapat diartikan sebagai keinginan atau kehendak (Sutiyono, 1998:63). Jika dipadankan kedua pemaknaan tersebut, wayang kayonan dapat bermakna sebagai kehidupan, dan dengan menancapakan kayonan pada babak awal ini, dalang menggambarkan bahwa kehidupan sudah dimulai serta menghidupkan wayang dengan cerita yang akan dibawakan sebagai persona dari tokoh dalam cerita. Setelah wayang Kayon ditancapkan di tengah-tengah kelir, lalu ditancapkan wayang Tintya atau sering disebut Acintya tanpa menari terlebih dahulu. Setelah itu, diikuti oleh tokoh wayang yang lain, seperti Yudhisthira, Bhima, Arjuna, Nakula, Sahadewa, Kunti, dan lain-lain, yang akan dipakai oleh dalang dalam pertunjukan tersebut. Semua wayang itu ditancapkan begitu saja, tanpa ada adegan menari terlebih dahulu.

Pada babak II, yaitu setelah semua wayang tadi dicabut, Kayonan ditarikan lagi. Pada saat itu, dalang mengucapkan prolog, yang disebut Penyacah Parwa. Prolog adDalam Penyacah Parwa itu, melalui wayang Kayon, dalang menceritakan kisah Bhima Swarga yang dikutip dari Epos Mahabharata, buah karya Bhagawan Krishna Dwipayana alias Bhagawan Wyasa.

Pada babak III, pada babak ini, keluarlah Wayang Dewi Kunti, diikuti Bhima, Tualen dan Merdah. Dalam pertemuan itu, Dewi Kunti membahas tentang persiapan melakukan upacara di Pemerajan. Dewi Kunti meminta kepada Yudhisthira, Arjuna, Nakula dan Sahadewa untuk membebaskan roh leluhurnya itu, Namun semua mengatakan tidak bisa berangkat ke sorga, Oleh karena itulah Dewi Kunti meminta kepada Bhima agar segera berangkat ke sorga untuk membebaskan roh leluhurnya itu. Bhima menyatakan bersedia melaksanakan perintah ibunya itu. Bhima lalu siap-siap berangkat ke sorga bersama Dewi Kunti dan semua saudarasaudaranya. Bhima mempersilahkan Dewi Kunti, Yudhisthira, Arjuna, Nakula dan Sahadewa untuk tinggal pada tubuhnya. Dei Kunti tinggal pada kepalanya, Yudhisthira pada mukanya, Arjuna di dadanya, dan Nakula serta Sahadewa di kedua lututnya kiri-kanan. Sedangkan Tulen yang berfungsi sebagai pengiring dan penerjemah, tidak ikut masuk ke badan Bhima. Tualen diperintahkan oleh Bhima agar berada di kancut (kamben) kain Bhima. Sedangkan Merdah masuk ke kantong Tualen. Dalam cerita disebutkan, Tualen punya kantong sakti yang dapat menampung manusia seperti Merdah. Dalam perjalanan itu, Bhima yang diiringi Tualen dan Merdah menemui beberapa roh yang menerima hukuman sebagai hasil perbuatan yang dilakukan di dunia fana.

Pada babak IV, ada pergantian cerita, yakni dijelaskan oleh narasi dalang melalui Kayon. Dalam narasi itu, dalang mengisahkan keadaan dan suasana sorga. Pada babak ini diawali dengan penggambaran tokoh atma. Monolog dan dialog dari tokoh atma memunculkan beberapa wacana dan telaah kritis dari penonton, terhadap apa yang boleh dan tidak boleh dilakukan di dunia ini berhubungan dengan hasil dari perbuatan yang akan diterimanya ketika di alam maya nantinya. Dalang dengan cermatnya menyusun wacana-wacana yang menimbulkan multiperspektif melalui dialognya. Jorgensen dan L.J Phipils (2007) menyatakan 
bahwa, dengan adanya wacana dari para tokoh yang ada dalam sebuah cerita ataupun pertunjukan dapat memberikan penggambaran yang kompleks terhadap dunia yang terdeskripsikan melalui pembicaraan. Terlebih lagi pertunjukan wayang dinyatakan mampu membangkitkan karsa dalam diri manusia, sehingga ia berkeinginan untuk melakukan perbuatan yang berguna bagi dirinya dan sekitarnya (Bastomi, 1993: 52). Setelah adegan atma berlangsung, kemudian keluarlah Delem dan Sangut. Mereka menceritakan dirinya sebagai abdi Bhatara Yama. Delem dan Sangut menerima roh atau atma yang datang ke sorga. Delem dan Sangut bercakap-cakap membahas tentang upacara ngaben dan sebagainya yang berhubungan dengan upacara kematian.

Pada babak V, dilanjutkan Bhima sedang dikisahkan berada di Tegal Penangsaran. Dalam perjalanan, mereka menemui berbagai rintangan yang disebut pengadang-ngadang. Bhima pun berperang dengan penghuni sorga. Sanghyang Suratma bertemu dengan Delem dan Sangut. Delem dan Sangut menceritakan, bahwa mereka bertemu dengan atma yang tidak dikenal berkulit hitam. Wayang Jogor Manik dan Sanghyang Yama juga keluar. Sanghyang Yama bertanya kepada Bhima, apa tujuannya ke sorga. Bhima menjelaskan bahwa tujuannya ke sorga untuk memohon agar roh Pandu dan Dewi Madri dibebaskan. Bhima memohon hanya dua atma, laki-perempuan. Sanghyang Yama mememenuhi permintaan Bhima. Bhima segera terjun ke kawah, untuk mencari atma Pandu dan Madri. Tetapi Bhima mengangkat banyak atma. Sanghyang Yama marah dan menantang Bhima untuk berkelahi. Tetapi Bhima mencekik Sanghyang Yama, dan Sanghyang Yama pun menyatakan bersedia mengambil atma Pandu dan Madri di dasar kawah. Namun janji itu tidak dilaksanakan. Kawah itu kemudian dibaik oleh Bhima. Ia hanya mendapatkan kotoron besi sebagai kerak kawah. Bhima kemudian memanggil ibunya Dewi Kunti, untuk memastikan apakah atma Pandu dan Dewi Madri itu berupa kerak kawah. Setelah yakin itu benar atma Pandu dan Madri, Bhima memanggil kakaknya, Yudhisthira, dan adik-adiknya Arjuna, Nakula dan Sahadewa.

Dewi Kunti memerintahkan agar Nakula dan Sahadewa menyembah dua atma itu. Setelah itu, kotoran besi itu menjadi tulang belulang Pandu dan dewi Madri. Kemudian pandawa lainya turut memberikan sembah. Kunti lalu memerintahkan Bhima untuk menyembah. Bhima menolak perintah ibunya. Ketika itu, Nakula dan Sahadewa memiliki siasat. Ia mengatakan, bahwa jeriji Bhima kanan-kiri tidak sama. Setelah Bhima mencakupkan tangan untuk memastikan ukuran jeriji tangannya, di saat itu dipandang sudah menghaturkan sembah. Setelah sempat marah, karena merasa ditipu, Bhima mohon tirta pawitra Dewata Nawa Sanga. Pertunjukan berakhir, tanpa perlu melanjutkan dengan kisah perjalanan Bhima Pulang. Kayon ditancapkan. Dalam pertunjukan LBS diakhiri dengan happy ending (kebahagiaan)

Secara keseluruhan struktur pertunjukan wayang kulit Bali LBS menggunakan alur maju. Alur maju merupakan alur yang secara representatif menampilkan jalan cerita dengan waktu yang tersusun dan struktur dramatik yang terjalin rapi. Struktur dramatik adalah hubungan antara beberapa bagian dramatic yang tersusun secara keseluruhan (Sudikan, 2001: 25). Rangkaian struktur dramatik dari pertunjukan ini menunjukan adanya klimaks pada pertengahan babak V, dimana terjadi perseteruan antara Bhima dengan Sanghyang Yama. Dan terdapat antiklimaks ketika adegan Bhima menuju istana (pulang) karena tugasnya sudah terselesaikan.

\section{Bentuk Penokohan Wayang dalam Pertunjukan Wayang Kulit Bali LBS}

Membahas persoalan bentuk wayang kulit Bali yang ada saat ini merupakan pengembangan dari bentuk-bentuk wayang klasik yang sudah mentradisi di Bali. Wayang klasik Bali yang memiliki pola khas menjadi aturan baku dalam rupa wayang klasik Bali, rupa tersebut ditenggarai sama dengan relief Hindu yang berada di Jawa Tengah (Putra, 2018: 135). Meskipun demikian, pertunjukan wayang kulit Bali karakter penokohan wayangnya tetap mengacu pada cerita yang dibawakan. Dalam pertunjukan wayang kulit Bali LBS yang 
merupakan cerita carangan sekalipun, tokoh tetap mengacu kepada cerita babon-nya (induknya) yaitu Mahabharata, kecuali tokoh parekan (punakawan) Tualen dan Merdah yang hanya ada dalam budaya Bali dan beberapa tokoh tambahan sebagai figuran seperti atma, dan penjaga neraka. Adapun tokoh-tokoh pelaku utamanya adalah sebagai berikut:

Tabel 1. Penokohan Wayang dalam Pertunjukan Wayang Kulit Bali LBS

\begin{tabular}{|c|c|c|}
\hline No & $\begin{array}{c}\text { Nama Tokoh dan } \\
\text { Gambar }\end{array}$ & Keterangan \\
\hline 1 & Wayang Kayonan & $\begin{array}{l}\text { Dalam budaya Jawa, Kayonan disebut Gunungan, karena } \\
\text { bentuknya menyerupai gunung. Dalam budaya Bali, } \\
\text { Kayonan juga ada yang menyebut Alas-alasan. Dalam } \\
\text { wayang Jawa, Gunungan bentuk ujung atasnya lebih lancip } \\
\text { daripada Kayonan wayang Bali }\end{array}$ \\
\hline 2 & Wayang & $\begin{array}{l}\text { Wayang Acintya sering pula disebut Wayang Tintya. Bentuk } \\
\text { wayang ini, paling kecil di anatara wayang yang ada. } \\
\text { Wayang ini berperan sebagai Tuhan Yang Maha Esa, yang } \\
\text { dalam kehidupan religius umat Hindu di Bali, disebut } \\
\text { Sanghyang Tunggal, Sanghyang Widhi Wasa, Sanghyang } \\
\text { Pramakawi, Sanghyang Tuduh, Sanghyang Embang, dan } \\
\text { beberapa sebutan lainnya. }\end{array}$ \\
\hline 3 & Wayang Bhima & $\begin{array}{l}\text { Bhima juga diberi nama Bhimasena, Wrekodara, } \\
\text { Blongkengares, Bayusuta. Bhima adalah putra dewi Kunti } \\
\text { berdasarkan permohonan dari Bhatara Bayu. Warna kulit } \\
\text { Bhima yakni hitam kemerah-merahan seperti warna kulit } \\
\text { manggis yang sudah matang. Tata rias Bhima, yakni } \\
\text { memakai gelung supit urang ada yang mengatakan Bhuawa } \\
\text { Sakula. Adapun kain yang dipakai adalah kain poleng hitam } \\
\text { putih yang dipakai dalam bentuk bulet/mabulet (kain yang } \\
\text { disimpulkan menyerupai bentuk celana dalam). Di } \\
\text { tangannya, memakai gelang kana berbentuk gada. Tokoh } \\
\text { Bhima versi wayang Bali memakai kalung ular poleng. }\end{array}$ \\
\hline 4 & & $\begin{array}{l}\text { Kunti, adalah istri Pandu. Kunti juga bernama Prtha. Kunti } \\
\text { adalah adik Wasudewa, ayah Sri Krishna. Wusudewa dan } \\
\text { Kunti adalah anak dari Prabu Surasena, wangsa Yodawa dari } \\
\text { Negara Kuntiboja. Dalam kehidupannya, Kunti memiliki } \\
\text { sifat keibuan yang tinggi. Begitu menjanda, Kunti } \\
\text { memelihara dan mendidik anaknya dengan penuh kasih } \\
\text { sayang. Berbagai penderitaan ia alami, seperti terbakarnya } \\
\text { rumah kardus, sehingga sempat mengembara dalam hutan. }\end{array}$ \\
\hline 5 & Yudisthira & $\begin{array}{l}\text { Dalam seni pedalanan Bali, Yudhisthira lebih dikenal dengan } \\
\text { nama Dharmawangsa. Dalam Epos Mahabharata, } \\
\text { Yudhisthira dinobatkan sebagai rajasuya, yaitu rajadiraja } \\
\text { yang memiliki kekuasaan luas karena kedudukannya di atas } \\
\text { raja. Ia memiliki sifat kenegarawanan yang tinggi, selalu } \\
\text { menginginkan kepentingan umum di atas kepentingan } \\
\text { pribadi }\end{array}$ \\
\hline
\end{tabular}




\begin{tabular}{|c|c|c|}
\hline 6 & Arjuna & $\begin{array}{l}\text { Arjuna memiliki banyak nama, antara lain Partha, } \\
\text { Dananjaya, Palguna. Putra Pandu ketiga ini lahir berdasarkan } \\
\text { permohonan Dewi Kunti kepada Dewa Indra. Arjuna } \\
\text { memiliki karakter pemberani, tekun bertapa, tampan. } \\
\text { Sebagai pencinta seni, Arjuna pernah sebagai guru tari di } \\
\text { Wirata, mengajar Dewi Uttari. Ia tekun bertapa sehingaa } \\
\text { memperoleh panah pasupati dari Dewa Siwa. Ketika belajar } \\
\text { memainkan senjata bersama saudaranya termasuk Korawa } \\
\text { dari Bhagawan Drona, Arjuna mendapat predikat murid } \\
\text { terbaik dalam memainkan senjata panah. }\end{array}$ \\
\hline 7 & Nakula dan Sahadewa & $\begin{array}{l}\text { Wayang yang digunakan untk Nakula dan Sahadewa adalah } \\
\text { sama. Hal tersebut dikarenakan mereka adalah saudarah } \\
\text { kembar. Nakula adalah saudara Pandawa yang keempat, } \\
\text { tetapi berlainan ibu dengan Yudhisthira, Bhima dan Arjuna. } \\
\text { Nakula adalah anak Dewi Madri. Dewi Kunti mengajarkan } \\
\text { ilmu untuk ngredana (memohon kepada Dewata) kepada } \\
\text { Dewi Madri. Sahadewa, saudara kembar Nakula, dan anak } \\
\text { paling bungsu dari Putra Pandu. Dalam penyamarannya di } \\
\text { Wirata, Sahadewa bernama Trantripada, dan bertugas } \\
\text { sebagai pengantar susu. Sahadewa merupakan putra Dewa } \\
\text { Aswino yang dikenal sebagai dukun di sorga. }\end{array}$ \\
\hline 8 & & $\begin{array}{l}\text { Pandu adalah putra Dewi Ambalika. Memiliki dua istri yaitu } \\
\text { Dewi Kunti dan Dewi Madri. Karakter Pandu menurut } \\
\text { Adiparwa, yakni adil dnn bijaksana, jujur, kesatria, teguh, } \\
\text { gemar berburu, menegakkan kebenaran, sayang istri dan } \\
\text { anak. Pada suatu hari, ia berburu ke dalam hutan. Oleh karena } \\
\text { memanah kijang (siluman Rsi Kindama), yang sedang } \\
\text { bersenggama, Pandu dikutuk. Kapan Pandu bersenggama } \\
\text { dengan istrinya, di saat itu ia menemui ajal. Pada akhirnya, } \\
\text { Pandu dan Madri melakukan pertemuan layaknya suami- } \\
\text { istri. Pada saat itulah Pandu tewas dan Madri melakukan } \\
\text { sastya, yakni menceburkan diri pada api pembakaran Pandu } \\
\text { sehingga ikut meninggal. }\end{array}$ \\
\hline 9 & & $\begin{array}{l}\text { Dewi Madri adalah adik Prabu Salya dari Kerajaan Madra. Ia } \\
\text { sangat mencintai suaminya, dan sangat sayang pada madinya } \\
\text { yakni Dewi Kunti. Pada waktu berburu ke dalam hutan, } \\
\text { Madri dan Kunti ikut sama-sama meladeni suaminya. Saking } \\
\text { cintanya pada suami, ia melakukan sastya, yakni terjun ke } \\
\text { dalam api pembakaran jenazah suaminyua sehingga sama- } \\
\text { sama ikut meninggal dunia. }\end{array}$ \\
\hline 10 & 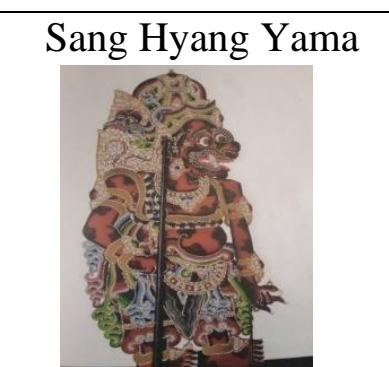 & $\begin{array}{l}\text { Sanghyang Yama adalah hakim agung di alam Pitra (sorga). } \\
\text { Sebagai hakim di Sorga, Yama dipandang juga sebagai Dewa } \\
\text { Keadilan di alam baka yang menghukum roh-roh. Senjatanya } \\
\text { adalah pedang, dan memiliki seekor anjing pelacak bermata } \\
\text { empat, dan seekor burung raksasa yang sangat buas. Dalam } \\
\text { budaya Bali, anjing peliharannya disebut Asu Gaplong, dan } \\
\text { burungnya disebut Paksiraja. Bentuk wayang Sanghyang }\end{array}$ \\
\hline
\end{tabular}




\begin{tabular}{|c|c|c|}
\hline & & $\begin{array}{l}\text { Yama yakni menyerupai raksasa, berbusana mewah, } \\
\text { memakai gelung candi kurung, berkuku panjang. }\end{array}$ \\
\hline 11 & & $\begin{array}{l}\text { Sang Suratma merupakan juru tulis sorga yang bertugas } \\
\text { mencatat semua perbuatan makhluk hidup di dunia ini. Roh } \\
\text { makhluk hidup di dunia akan mendapat hukuman sesuai } \\
\text { dengan hasil perbuatannya. Dalam seni pedalangan Bali, } \\
\text { Sang Suratma sering ditampilkan sebagai tokoh yang kocak, } \\
\text { sering berbahasa Bali kepara. Ia tidak memakai gelung, } \\
\text { rambutnya berkuncir seperti tokoh punakawan Sangut. }\end{array}$ \\
\hline 12 & Sang Jogor Manik & $\begin{array}{l}\text { Jogor Manik, adalah tokoh yang ditugaskan oleh Sanghyang } \\
\text { Yama sebagai penjaga kawah panas Candragomuka. Ia } \\
\text { menyerupai raksasa, dan tugasnya sebagai eksekutor, yakni } \\
\text { menjatuhkan hukuman bagi roh jahat atas perintah } \\
\text { Sanghyang Yama berdasarkan laporan Sang Suratma. }\end{array}$ \\
\hline 13 & & $\begin{array}{l}\text { Tualen sering pula disebut Malen. Ia adalah punakawan } \\
\text { wayang dipihak kanan, seperti Pandawa dalam epos } \\
\text { Mahabharata dan Rama dalam epos Ramayana. Tualen } \\
\text { digambarkan berwajah bocok (buruk), berkulit kehitam- } \\
\text { hitaman, tetapi sangat sakti, tidak terbunuh dalam perang. } \\
\text { Fungsinya dalam seni pedalangan, antara lain sebagai } \\
\text { penerjemah, penasihat dan bahkan pernah menjadi tokoh } \\
\text { utama. }\end{array}$ \\
\hline 14 & & $\begin{array}{l}\text { Merdah adalah punakawan yang dikisahkan sebagai anak } \\
\text { Tualen. Merdah juga sering dipanggil Wredah, Dalam } \\
\text { wayang kulit versi Buleleng, Merdah juga disebut Wana. } \\
\text { Karakter Merdah adalah pemberrani, setia, tangkas, kuat. } \\
\text { Bentuknya kecil dengan hidung bulat. }\end{array}$ \\
\hline 15 & & $\begin{array}{l}\text { Delem adalah punakawan wayang di pihak kiri, atau } \\
\text { berlawanan dengan Pandawa dalam epos Mahabharata atau } \\
\text { Rama dalam epos Ramayana. Karakter Delem dalam seni } \\
\text { pedalangan Bali yakni antara lain: sombong, kasar perilaku } \\
\text { dan bicaranya, mengaku paling hebat, suka menghina orang } \\
\text { lain. Ciri bentuk Delem yang khas adalah, lehernya gondok. } \\
\text { Dibandingkan dengan wayang Jawa, Delem sering } \\
\text { disamakan dengan Bagong. }\end{array}$ \\
\hline 16 & & $\begin{array}{l}\text { Sangut juga punakawan wayang di pihak kiri. Dalam seni } \\
\text { pedalangan Bali, Sangut diceritakan sebagai adiknya Delem. } \\
\text { Karakter Sangut berbeda dengan Delem. Ia memiliki banyak } \\
\text { tutur, sehingga sering memberi nasihat kepada Delem. Juga } \\
\text { memiliki welas asih atau iba, ketika melihat ada orang disiksa } \\
\text { ataun dibunuh baik di pihak mush lebih-lebih di pihak } \\
\text { kawan, jika orang itu tak bersalah. }\end{array}$ \\
\hline
\end{tabular}

(Sumber: Dokumentasi Peneliti, 2021) 


\section{Bahasa dan Vokal dalam Pertunjukan Wayang Kulit Bali LBS}

Berdasarkan pengamatan dan keterangan dari informan, iringan yang berupa vokal dalam kesenian wayang kulit dapat dibedakan menjadi dua golongan yaitu: (1) Sasendon yaitu suatu tembang yang dipakai oleh wayang Kayon dan beberapa tokoh wayang, (2) Pangalangkara yaitu narasi yang dipakai untuk mengungkapkan cerita dalam pertunjukan, baik disampaikan melalui kayon maupun oleh dalang sendiri. Keseluruhan aspek vokal yang digunakan masih menggunaka tembang atau gending-gending tembang atau gending-gending yang kental dengan suasana Hindu (Mulyono, 1978: 57). Sasendon yang digunakan dalam seni pertunjukan wayang kulit, sebagian besar diambil dari bait kakawin yang mengisahkan epos Ramayana dan Epos Mahabharata.

Kemudian penggunaan bahasa dalam LBS, sama dengan seni pertunjukan wayang kulit pada umumnya, yakni menggunakan Bahasa Kawi dan Bahasa Bali. Tokoh wayang sekelas raja dan tokoh yang penampilannya tidak pernah menampilkan adegan lucu, memakai Bahasa Kawi. Sedangkan sejumlah tokoh yang bisa menampilkan adegan lucu dan semua punakawan memakai Bahasa Bali dan jarang memakai Bahasa Kawi. Dalam LBS, tokoh wayang yang menggunakan Bahasa Kawi adalah, Dewi Kunti, Yudhisthira, Bhima, Arjuna, Nakula, Sahadewa, Sanghyang Yama, Sang Suratma, Jogor Manik. Namun adakalanya, Sang Suratma dan Bhima menggunakan Bahasa Bali ketika berbicara kepada tokoh tertentu. Sedangkan punakawan Tualen, Merdah, Delem dan Sangut menggunakan Bahasa Bali, terutama ketika menerjemahkan bahasa yang diucapkan junjungannya atau yang diiringinya. Jika dalang menyampaikan lelucon diluar konteks cerita, punakawan adakalanya memakai bahasa asing atau bahasa selain bahasa Kawi dan bahasa Bali. Pemilihan penggunaan bahasa pada pertunjukan wayang kulit Bali LBS didasarkan pada pola pertunjukan tradisi yang sudah berbentuk pakem wayang, selain itu untuk mengefektifkan penggunaan bahasa perlu diadakan penerjemah bahasa Kawi-Bali dalam pertunjukanya yang dilakukan oleh punakawan. Pemilihan materi bahasa oleh punakawan didasarkan pada aspek penonton. Dalang selalu berusaha untuk mencermati penontonya. Menurut Narta, jika yang menonton pertunjukan adalah anak muda, maka akan disisipkan bahasa-bahasa kekinian. Purnamawati (1997:3) menyatakan bahwa, pemilihan materi bahasa tidak boleh merubah makna cerita, melainkan pemilihan materi bahasa yang tepat adalah dengan menyampaikan gagasan yang terkandung dalam cerita secara tepat.

\section{Musik Iringan Pertunjukan Wayang Kulit Bali LBS}

Seni pertunjukan wayang kulit LBS, lebih sering dipergelarkan pada upacara yadnya, terutama Pitra Yadnya, baik dipertunjukkan pada malam hari atau siang hari. Jika dipertunjukan pada malam hari, pertunjukan tersebut dinamakan dengan wayang peteng, jika di siang hari disebut wayang lemah (Agung, 1981: 53). Oleh karena lakon yang dibawakan diambil dari Mahabharata, maka jenis wayang ini disebut Wayang Parwa. Dalam pertunjukan Wayang Parwa iringan musik yang digunakan adalah lebih sering terdiri dari empat tungguh (buah) gender wayang. Gender wayang merupakan salah satu instrument gamelan Bali dengan bilah berjumlah sepuluh dan berlaraskan selendro. Gender wayang dimainkan dengan menggunakan kedua tangan memengang panggul gender, dengan teknik nekep langsung menggunakan perut telapak tangan bagian bawah. Gender wayang juga sering digunakan untuk kegiatan lainya di Bali seperti mesangih (upacara potong gigi) dan ngaben (upacara kremasi) (Arsana, 2014: 110). Jika pada wayang lemah, untuk efisiensi, sering pula hanya memakai dua tungguh gender saja. Dibia (2012: 122) juga menyebutkan, minimal gender wayang dalam pertunjukan wayang lemah dimainkan oleh dua orang, satu orang dengan satu tungguh gender memainkan pola polos, dan satunya lagi memainkan pola sangsih.Dalam perkembangannya kemudian, jenis wayang ini terkadang diiringi oleh seperangkat angklung, dan barungan (ansamble) gemelan yang lebih besar seperti Semara Pegulingan. Hal itu dilakukan karena 
pertimbangan terknis. Misalnya, pada upacara Pitra Yadnya memakai gamelan angklung. Jika penabuh angklung tersebut juga bisa memainkan gamelan angklung, maka merekalah yang mengiringi wayang. Demikian pula gamelan samara pegulingan, jika mereka juga sering mengiringi pertunjukan wayang kulit, merekalah yang mengiringi.

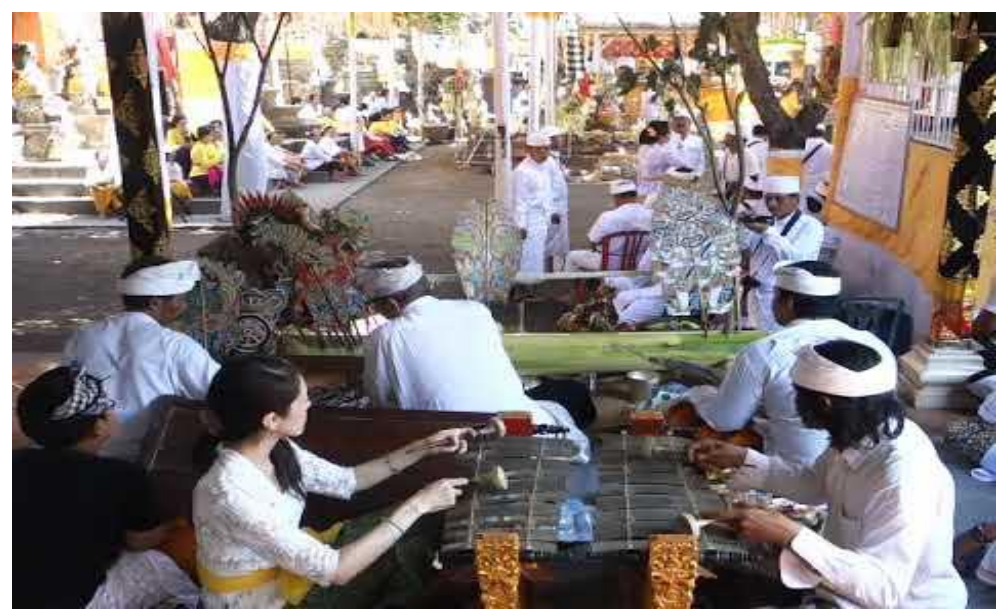

Gambar 1. Penabuh Gamelan Samara Pegulingan

\section{Sesajen yang Digunakan Dalam Pertunjukan}

Kesenian wayang kulit Bali dengan mengangkat LBS berfungsi sebagai bebali, artinya sebagai pelengkap upacara. Disebut sebagai pelengkap upacara, karena, pertunjukan ini bisa diselenggarakan, dan juga bisa tidak ada, tergantung pada situasi dan kondisi. Hal ini berbeda dengan Wayang Sapuhleger, yakni pertunjukan wayang untuk keperluan upacara untuk seseorang yang lahir pada Wuku Wayang. Pada upacara itu, pertunjukan wayang harus dilakukan, sehingga fungsi wayang dalam konteks ini yakni sebagai seni wali.

Dalam pertunjukan wayang kulit Bali LBS, sesajen yang digunakan terdiri dari banten untuk gender, untuk pertunjukan wayang dan sesajen untuk nunas tirtha wayang. Berdasarkan pengamatan, tidak ada ketentuan yang pasti tentang nama atau jenis sesajen yang digunakan. Selain adanya perbedaan tradisi, kepercayaan, juga tergantung pada situasi dan keadaan di tempat pertunjukan. Akan tetapi intinya tetap sama, yakni persembahan yang mengandung unsur daun, bunga, buah, air dan di Bali, juga memakai daging atau ikan.

Sesajen wayang kulit yang sering digunakan untuk pertunjukan wayang kulit yakni secara garis besar dibagi dua. Ada sesajen yang ditempatkan di atas dalam panggung dan ada yang di bawah. Sesajen yang berada di atas, dipersembahkan kehadapan Taksu dan Bhatara Samodaya. Sesajen yang dipersembahkan antara lain: pras, lis, daksina, banten taksu, canang sari, katipat kelan, punjung rayunan, suci asoroh maiwak itik putih, panyeneng, tehenan, ajuman, canang gantal, banyuawang, pedupaan, lengawangi, buratwangi. Dulang medaging sangku utawi payuk anyar madaging toya anyar, matatakan beras, toya cendana samsam, bija kuning, bunga 11 warna, utamine sekar tunjung putih, pipis 250, lis wayang gede. Sesajen itu dipersembahkan dengan tujuan, memohon kepada Ida Taksu (manifestasi Tuhan sebagai Dewa Kesenian), agar dianugerahi keselamatan, kelancaran dan suksesnya pertunjukan dan penonton merasa terhibur.

\section{Bentuk Panggung Pertunjukan}

Dalam pertunjukan apapun, pasti memerlukan tempat. Di Bali, tempat pertunjukan wayang kulit disebut panggung. Bisa bentuknya seperti rumah panggung, dan juga bisa menggunakan panggung yang biasa digunakan dalam pertunjukan seni petunjukan drama, atau seni tari lainnya. Jika pertunjukan ini dilakukan di rumah penduduk, juga bisa digunakan sebuah ruangan tamu. Hal itu disebabkan, tempat pertunjukan LBS dengan memakai empat 
gender, tidak memerlukan tempat atau panggung yag luas. Apalagi, jika tempat upacara juga tidak memiliki areal yang luas. Tempat pertunjukan seluas tiga kali empat meter persegi, sudah cukup untuk mementaskan wayang kulit ini. Tempat itu digunakan untuk memasang kelir pada wayang peteng (jika pertunjukan di malam hari) sepanjang tiga meter (panjang kelir sekitar 2,5 meter), dan selebihnya untuk dalang, menaruh gedog dan tempat empat tungguh gender. Dalam panggung tersebut juga digantungkan blencong, yakni lampu yang memakai bahan bakar minyak kelapa, bersumbu dari benang kapas atau sumbu kompor minyak tanah. Meskipun dengan pengaturan yang sangat sederhana, namun penataan panggung menjadi sebuah kunci suksesnya pertunjukan. Khususnya pada pertunjukan wayang kulit Bali yang mengutamakan vokal dalang, maka bagian dialog harus dapat didengar jelas oleh penonton meskipun tanpa menggunakan alat pengeras suara.

Sidharta dan Arifin (2014: 50) menyatakan bahwa sebuah tempat pertunjukan harus memiliki pengaturan ruang suara yang baik agar dialog dapat didengar dengan baik. Penataan panggung dengan penempatan berbagai macam instrumen pada pertunjukan wayang kulit Bali dilakukan secara sederhana dengan menyesuaikan ketersediaan tempat. Namun penataan tersebut tetap mengindahkan aspek tata ruang suara meskipun dalam pelaksanaan upacara Pitra Yadnya yang ramai dengan kemhadiran masyarakat. Adapun penataan panggung pertunjukan pertunjukan wayang kulit Bali LBS dapat dilihat pada gambar berikut:

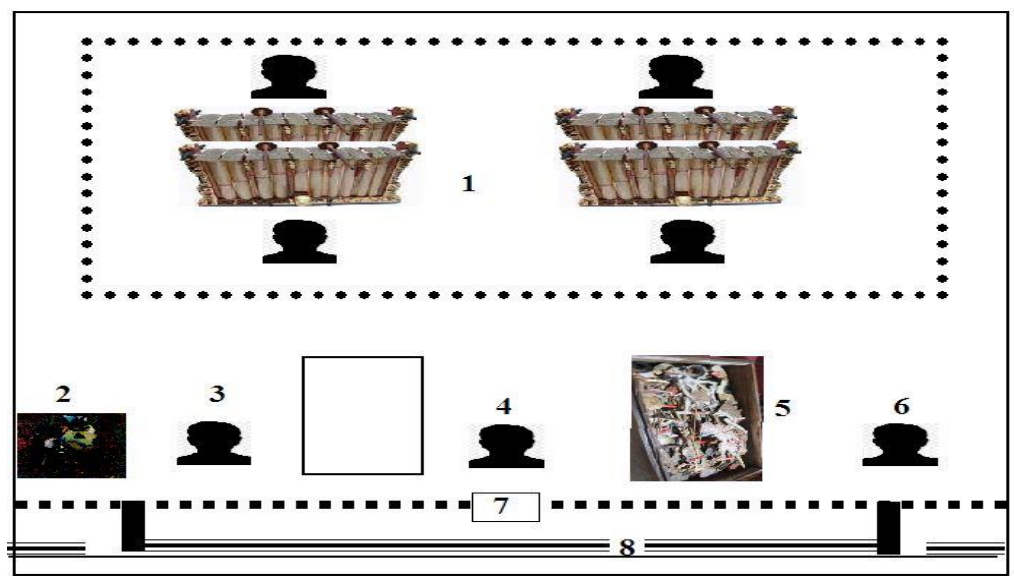

Gambar 2. Penataan Panggung Pertunjukan Wayang Kulit Bali LBS

(Sumber: Peneliti, 2021)

Keterangan:

1. Gender wayang dan tukang gender 2. Sesajen wayang

3. Katengkong

5. Gedog dan wayang

7. Blencong

4. Dalang

6. Katengkong

8. Kelir wayang dan gedebong (batang pisang).

Dalam pertunjukan wayang lemah, sebagai pengganti kelir adalah benang tukelan, yakni sekumpulan benang yang terbuat dari kapas, yang khusus dipakai dalam upacara agama Hindu di Bali, Indonesia. Benang tukelan ini diikatkan pada dua carang (ranting) dapdap tis. Bentuk benang tukelan ini agar kasar, besar, dan tidak bisa dipakai untuk menjarit pakaian. Benang tukelan ini selain sebagai pengganti kelir, juga dipakai untuk sumbu blecong. Selain itu juga dipakai gelang dan simbol bunga dalam upacara Manusa Yadnya, misalnya upacara tiga bulalan, otonan (enam bulan), atau upacara yang berkaitan dengan upacara penyucian. Gelang benang itu digunakan untuk sementara waktu saja, misanya hanya tiga hari atau sudah putus sendiri.Jika digunakan untuk lambang kelir wayang, di kedua ujung benang tersebut digantungkan pis bolong satakan, yaitu uang kepeng yang jumlahnya 200 keping di masingmasing ujung benang. Dalam perkembangannya kemudian, selain benang tukelan, juga 
ditambahkan dengan benang tridatu. Benang tri datu ini adalah tidak benang masing-masing berwarna merah, putih dan hitam. Warna itu melambangkan Dewa Tri Murti, yakni merah melambangkan Dewa Brahma, hitam melambangkan Dewa Wisnu, dan putih melambangkan Dewa Siwa. Adapun contoh bentuk panggung wayang lemah dapat dilihat pada gambar berikut:

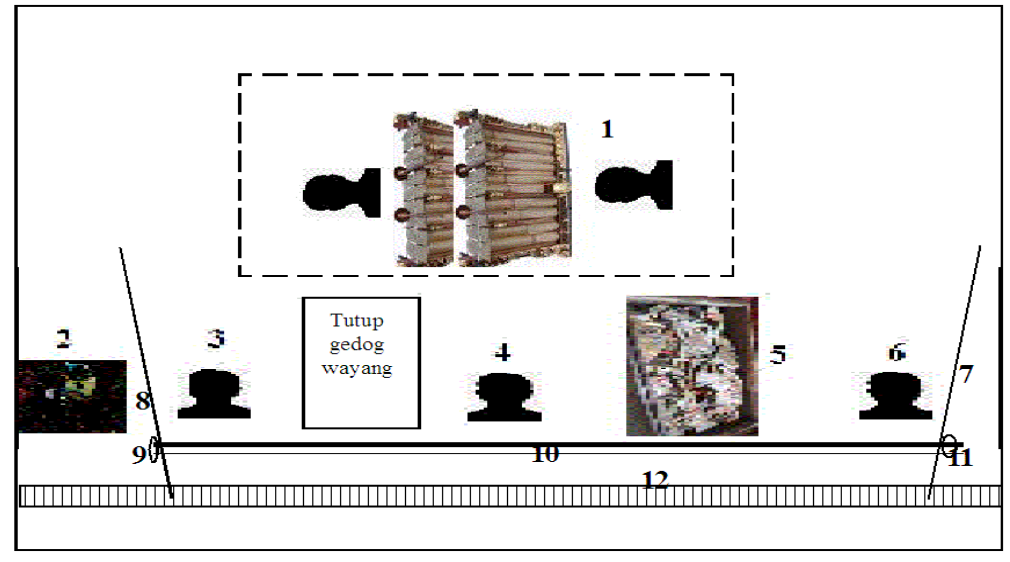

Gambar 3. Bentuk Panggung Wayang Lemah

(Sumber: Peneliti, 2021)

Keterangan:

1. Gender dan tukang gender

2. Banten wayang

4. Dalang

5. Gedog dan wayang

7. Carang Dapdap

8. Carang Dapdap

10. Benang Tukelan

11. Pis Bolong Satakan

6. Katengkong 2

9. Pis Bolong Satakan

12. Gedebong

\section{Simpulan}

Pertunjukan wayang kulit Bali LBS sebagai sebuah pelengkap sarana ritual dalam upacara pitra yadnya sangatlah erat kaitanya, jika ditinjau dari cerita yang dibawakan dengan konteks upacara pitra Yadnya, yakni penyucian Sang Atma. Penggambaran tokoh Bhima sebagai tokoh sentral yang membebaskan roh leluhurnya di dasar kawah neraka dapat menjadi sebuah contoh sebagai sebuah usaha untuk menghormati leluhur. Sebagai sebuah pertunjukan pada upacara yadnya, Adapun temuan bentuk pertunjukan wayang kulit Bali LBS dibagi dalam pembahasan mengenai, 1) sinopsis pertunjukan wayang kulit Bali LBS, 2) Struktur pertunjukan wayang kulit Bali LBS yang tebagi kedalam 5 babak secara keseluruhan, 3) Bentuk penokohan wayang dalam pertunjukan wayang kulit Bali LBS dengan jumlah penokohan sebanyak 17 wayang, 4) Bahasa dan Vokal dalam pertunjukan wayang kulit Bali LBS, terkait Bahasa yang digunakan dalam pertunjukanya adalah Bahasa Kawi dan Bahasa Bali, sedangkan aspek vokalnya adalah sasendon dan panglangkara, 5) Musik iringan pertunjukan wayang kulit Bali LBS, dengan menggunakan empat tungguh gender wayang dalam pertunjukan wayang lemah, dan penggunaaan barungan gamelan Semar Pegulingan pada pertunjukan wayang peteng, 6) Sesajen yang dipergunakan dalam pertunjukan yang terbagi menjadi 3 , yakni sesajen untuk gender, pertunjukan wayang, dan nunas tirtha wayang 7) Bentuk panggung pertunjukan yang berbeda antara pertunjukan wayang lemah dan wayang peteng.

\section{Daftar Pustaka}

Agung, A. A. G. P. (1981). Beberapa Tari Upacara dalam Masyarakat Bali. Jakarta: Dirjen Kebudayaan, DEPDIKBUD.

Ardana, I. K. (2020). Representas Konsep Patet dalam Garap Gamelan Bali. Resital: Jurnal Seni Pertunjukan, 21(1), 11-28. 
Arnailis. (2007). Kesenian Ilau di Nagari Salayo Sumatera Barat: Suatu Kajian Bentuk, Fungsi dan Makna. Tesis, Universitas Udayana.

Arsana, I N. C. (2014). Kosmologis Tetabuhan dalam Upacara Ngaben. Resital: Jurnal Seni Pertunjukan, 15(2), 107-125

Awalin, F. R. N. (2018). Sejarah Perkembangan dan Perubahan Fungsi Wayang dalam Masyarakat. Jurnal Kebudayaan 3(1), 77-89

Bastomi, S. (1993). Nilai-Nilai Seni Pewayangan. Semarang: Dahara Prize.

Dibia, I W. (1995). Dari Wacak ke Kocak. Mudra: Jurnal Seni Budaya (No. 3, Tahun 3), 5168.

Dibia, I W. (2012). Ilen-Ilen Seni Pertunjukan Bali. Denpasar: Balimangsi Foundation

Esslin, M. (2008). Teater Absurd. Mojokerto: Pustaka Banyumili.

Joergensen, M.W., L.J. P. (2007). Analisis Wacana: Teori dan Metode. Yogyakarta: Pustaka Pelajar.

Masroer, Ch. Jb. (2015). Spiritualitas Islam dalam Budaya Wayang Kulit Masyarakat Jawa dan Sunda. Jurnal Ilmiah Sosiologi Agama 9(1), 38-61.

Mulyono, S. (1989). Wayang dan Filsafat Nusantara. Jakarta: Gunung Agung.

Poespaningrat, P. 2005. Nonton Wayang dari Berbagai Pakeliran. Yogyakarta: PT. BP. KR.

Prayoga, D. S. (2018). Peran Dalang dalam Seni Pertunjukan Wayang Kulit. In Prosiding Seminar Nasional Manajemen, Desain \& Aplikasi Vol. 1. (pp. 210-217).

Purnamawati, N. D. (1997). Retorika dalam Pertunjukan Drama Gong Bintang Bali Timur dengan Lakon Ni Luh Sukerti. Denpasar: STSI Denpasar.

Putra, I D. A. D. (2018). Menelusuri Jejak Rupa Wayang Klasik Bali. Jurnal Rupa: Jurnal of Art, Craft, and Visual Culture 03(2), 130-149.

Sidharta, N. A. (2014). Gedung Pertunjukan Seni Teater Tradisional Jawa di Surabaya. eDimensi Arsitektur Petra, 2(1), 44-51.

Sudikan, S. Y. (2001). Metode Penelitian Sastra Lisan. Surabaya: Citra Wacana.

Sugiartha, I. G. A. (2015). Bentuk dan Konsep Estetik Musik Tradisional Bali. Resital: Jurnal Seni Pertunjukan 23(1), 46-60.

Zoetmulder, P. J. (1994). Kalangwan: Sastra Jawa Kuno Selayang Pandang. Terjemahan Dick Hartoko. SJ. Jakarta: Djambatan. 